\title{
Building a Framework for Analysing the Quality of Life at Neighbourhood Level: An Empirical Case from Ankara
}

\author{
"Ezgi Orhan', Z Ezgi Kahraman² and Nazda Güngördü ${ }^{3}$
}

\begin{abstract}
Published online: 15 July 2020
To cite this article: Ezgi Orhan, Z Ezgi Kahraman and Nazda Güngördü (2020). Building a framework for analysing the quality of life at neighbourhood level: An empirical case from Ankara. Journal of Construction in Developing Countries, 25(1): 63-82. https://doi.org/10.21315/jcdc2020.25.1.4.
\end{abstract}

To link to this article: https://doi.org/10.21315/jcdc2020.25.1.4

\begin{abstract}
This article aims to analyse the indicators of quality of life (QOL) in a regeneration area in line with the subjective evaluations of neighbourhood residents. To this end, a total of 359 respondents were selected by random sampling in the Akpinar neighbourhood, Ankara, Turkey which was inhabited by squatter settlements and subjected to urban regeneration resulting in a substantial change in its physical, social, spatial and demographic structure. The neighbourhood was challenged by a landslide after the urban regeneration which affected the satisfaction levels of residents and constituted a contradiction for regeneration efforts. It is hypothesised that the QoL of neighbourhood residents is affected by the factors of quality of the built environment, public spaces, social environment, natural environment, services and facilities and safety. The findings indicate that neighbourhood level QoL is positively associated with the width of streets, adequacy of parking lots, adequacy of cultural facilities, adequacy of sewage and drainage systems, discreetness of inhabitants and peace and calmness in the neighbourhood. The present research contributes to the development of a more comprehensive schema for regeneration practices by considering both objective and subjective indicators and by revealing the importance of the public space's influence on the QoL for urban residents.
\end{abstract}

Keywords: Quality of life, Neighbourhood design, Public well-being, Regeneration, Perception

\section{INTRODUCTION}

Urban regeneration is regarded as an effective means in achieving public wellbeing and in promoting general welfare (Roberts and Sykes, 2000). Regeneration initiatives, when applied properly, have introduced purposeful and well-intentioned schemes for the solution of certain problems in existing urban areas ranging from housing improvement, education and health gains, and crime reduction. Being a significant tool of planners in reducing social inequalities, urban regeneration projects mainly address the deprivation in the urban fabric, economic structure and social facilities. Since "planners must protect and enhance the quality of life (QoL) as a strategic source for supporting continued development and for the future satisfaction of citizens" (Myers, 1988: 356), planners are supposed to consider liveability and enhance quality for local people in urban regeneration projects.

In the academic domain, scholars suggest that regeneration efforts address the core issues of providing jobs, public services, housing, QoL in safe and physically sound urban areas, but policymakers are likely to face a number of problems

\footnotetext{
'Department of City and Regional Planning, Balgat Campus, Cankaya University, Cankaya, Ankara, TURKEY 2Department of City and Regional Planning Cankaya University, Cankaya, Ankara, TURKEY

"Corresponding author: ezgiorhan@cankaya.edu.tr
} 
(Roberts and Sykes, 2000). One of the most concrete problems is to evaluate the success of regeneration objectives. Alberini, Riganti and Longo (2003) state that urban regeneration projects, in addition to their monetary benefits, provide nonmarket goods such as aesthetic quality, comfort, identity, heritage preservation and access to outdoor space. Measuring the benefits of regeneration projects in such terms, undoubtedly, helps us uncover the success of the projects. Therefore, assessing the QoL is worthwhile in a regenerated area to understand the gains in social, economic, environmental and spatial terms.

This article addresses urban QoL in regenerated areas through a case study in the Akpinar neighbourhood of Ankara. With a population of 12,114 inhabitants, Akpinar is located in the southern part of the city, $7 \mathrm{~km}$ from the central business district. In earlier times, the neighbourhood was inhabited by low-income groups, mostly migrated from less developed and rural parts of the country, to be close to the job opportunities that the city provided. The initial cityscape was composed of squatter housing built on the slopes of an inconvenient topography. Squatter houses used to be single or two-storey dwellings built with relatively cheap materials. After the 1990s, these houses were replaced by detached apartments or apartment blocks by small and medium scale contractors; this development occurred due to the squatter areas' advantageous location close to the city centre, the new highways and commercial developments. By this model of transformation, both the housebuilders and the right-holders, i.e. former squatter residents, became shareholders of apartment buildings (Kahraman, 2013). However, some of them moved out of the area by renting or selling their houses. The new inhabitants of the area belonged to the middle-and high-income group and began to reside in the apartments, which have moderate construction and material quality. Apart from the regeneration efforts, another significant process affecting the spatial formation of the neighbourhood was initiated by a natural disaster. A landslide event hit the neighbourhood, damaging a group of seven apartment blocks. In 2013, the site was declared an area of risk by the Ministry of Environment and Urbanism, due to its building conditions and geological structure. Following the decision on the unsuitability of the area for settlement, the area was functioned as green space, 308 inhabitants were evacuated from the risk zone and a reserved area in the neighbourhood was allocated where the affected households would be given the right to settle in new apartments.

The selected neighbourhood exemplified the site, with a dynamic population due to land redevelopment and departures after the landslide. Moreover, the neighbourhood had the potential to combine physical, social, economic and environmental considerations. Likewise, this case study contributed to the use of these indicators as a means of quantifying the outputs of area-based regeneration. Rather than presenting a discussion on property-led redevelopment and the consequences of economic regeneration, this article focuses on a comprehensive framework and a case area providing a variety of challenges that may affect people's well-being.

This article is structured around the following research question: "Which underlying factors determine the QoL in a regenerated neighbourhood?". In order to approach the research question, a review of previous QoL studies was presented and in this way, a comprehensive list of indicators was obtained. Those indicators constituted the basis of the empirical research designed to evaluate the liveability of a neighbourhood. The present research contributes to the development of a more comprehensive schema for regeneration practices by considering both 
objective and subjective indicators and by revealing the importance of the public space's influence on the QoL for urban residents.

\section{REVIEW OF QOL STUDIES}

\section{Understanding QoL}

The term "quality of life" has numerous definitions based on its multidisciplinary, complex and dynamic dimensions. The concept has been studied on various scales and analysed through subjective and objective indicators, which in turn result in a series of definitions and attributes that are context and scale-dependent. To reflect on its various dimensions, the term QoL is interchangeably interrogatively used with concepts such as well-being, happiness, liveability, environment quality and life satisfaction, each of which is a broader sense constitutes an integral part of the term (Diener and Suh, 1997). Liveability is the attractiveness of a district, associated with the residents' perception and evaluation of the living environment concerning health, social amenity and well-being at individual and community levels. Pacione (2003: 20) defines liveability as the "behaviour related function of the interaction between environmental characteristics and personal characteristics".

Due to the comprehensiveness of the term, which refers to both the conditions of the environment in which people live and their satisfaction from these environments (Pacione, 2003; Myers, 1988), various categorisations appear in the literature on measuring the QoL. The most common set of definitions derived from the distinction include individual and communal senses of QoL. In this respect, individual QoL indicates the feelings and emotions in well-being (Shin and Johnson, 1978) and satisfaction (Campbell, Converse and Rodgers, 1976) that are subjective and originate from several events and interactions with outer spaces. The emphasis is on the interaction between individual and environment required to develop a communal understanding in explaining overall assessment of one's current life conditions with respect to his/her desires, expectations and needs.

Despite its origins dating back to Aristotle (384-322 B.C.), who incorporated the "good life" and "living well" into public policy discussions (El Din et al., 2013), in the academic domain, emphasis on QoL at a communal level started after World War II with the emergence of the welfare state (Zehner, 1977). Until the 1980s, the quality of modern living was accepted as a simple function of material wealth. Gross Domestic Product (GDP) is the most common measure of economic activity; it is used widely as a significant indicator of economic performance and living standards at a national level. However, as the emphasis of QoL changes from material wealth to social progress, the components of perceived well-being need to be both objective and subjective to understand the different patterns of appropriation. In this respect, scholars developed satisfaction models that employ both objective attributes and perceived or subjective attributes to comprehensively understand public wellbeing (Marans, 2003). The nested nature of subjective and objective dimensions of satisfaction has inevitably brought along a "communal" understanding of wellbeing which heavily depends upon environmental satisfaction.

In the 1970s, the geographic dimension of the term came to the fore to address the increasing socio-economic disparities and unjust conditions. In the 1980s, a group of studies were dedicated to the geography of QoL measured on various scales: national, regional, city and neighbourhood. This spatial focus has 
been primarily the concern of life satisfaction and well-being discussions at an urban level (Sedaghatnia et al., 2013). According to McCrea (2007), the QoL derived from an urban environment refers to different aspects of life including satisfaction from housing or neighbourhood. In the planning discipline, this conceptualisation has found an extensive basis, since it is highly measurable through focusing on single/ narrowed aspects of life (as objective indicators) and relatively missing outsole subjective evaluations, including emotions and feelings.

\section{Measuring QoL}

Objective indicators of QoL are mostly derived from national/institutional statistics and the legal databases of the given locality, which can be universally evaluated and compared (Sedaghatnia et al., 2013). Objective indicators may also be obtained from pre-organised experiments and tests or long-term researches measuring the amount, level or frequencies of given trends and factors such as pollution, crime rates, housing prices, literacy rate, number of households, unemployment rates, distance from the city centre, etc. (Sedaghatnia et al., 2013). In these studies, objective indicators are usually weighted in a way to reflect urban environments to rank or compare different countries and/or localities (Diener and Suh, 1997). Providing general information about different contexts, such rankings and comparisons are criticised for being neither objective nor reliable since the weighting procedure may depend upon subjective evaluations and the assumptions of researchers (Marans, 2003) and since different results may be obtained through using different sets of indicators with different weights (Sedaghatnia et al., 2013). The deficiencies of objective QoL measurements bring about the need to use subjective indicators that are developed to measure personal opinions, evaluations, expectations and level of life satisfaction (McCrea, 2007).

Recently, studies combining subjective and objective indicators have had uppermost importance in planning literature, since subjective evaluations enable researchers to take into account social, cultural and spatial contexts of a given locality in measuring QoL while testing the validity or reflection of observable facts in neighbourhoods. This also enables researchers to develop tailor-made policies based on personal/communal expectations as well as highly accessible national/ local datasets and statistics about problematic fields (McCrea, 2007).

Although there is a common view in the literature that both subjective and objective indicators can be meaningful in addressing QoL, as Hemphill, Berry and McGreal (2004) state, the selection of appropriate indicators for regeneration projects is difficult, since these indicators are sensitive to locational factors. Accordingly, the subjective attributes of this study decided upon to explain life quality include: (1) quality of built environment, (2) quality of public spaces, (3) quality of social environment, (4) quality of natural environment, (5) safety and (6) quality of services. Supplementing the analysis of previous researches for indicator construction, this study evaluates the QoL by focusing on its different aspects at a neighbourhood level.

As the first set of QoL dimensions, quality of the built environment refers to both indoor and outdoor environments in terms of aesthetics, functionality, volume and density (e.g. Gür and Dostoğlu, 2016; Lee et al., 2016; Schlesinger et al., 2016). Living in a healthy neighbourhood having an average density of housing and good quality of architectural design and building materials increases the level of happiness 
and satisfaction. On the other hand, the bad structural and internal quality of housing, the need for frequent maintenance, dust, dirt and heating problems and irregular high-density urbanisation have negative impacts on well-being, health and satisfaction (Kahraman, 2013; Batson and Monnat, 2015; Lee et al., 2016). The aesthetic value and design of the built environment are claimed to be important factors in shaping inhabitants' opinions of their neighbourhoods and are positively correlated with overall neighbourhood satisfaction (Bonaiuto, Fornara and Bonnes, 2003; Novianto et al., 2016). However, the relationship between building volume, density and QoL is quite complicated. On the one hand, high density is regarded as an asset since it brings along more diversity and functional varieties and thus more accessible services and amenities. On the other hand, some scholars associate building density and volume with increasing urbanisation and accompanying social and environmental issues such as crime and pollution (Lee et al., 2016).

Quality of public spaces is another dimension of QoL at the neighbourhood level that has been discussed largely in the literature (Salleh, 2008; Mohit, Ibrahim and Rashid, 2010; El Din et al., 2013; Lee et al., 2016; Novianto et al., 2016). The existence of open and green areas in neighbourhoods, their quality, maintenance and functionality are proved to be positively correlated with overall life satisfaction (Ewing et al., 2006; Okumuş and Eyüboğlu, 2015; Lee et al., 2016). Moreover, the accessibility of the environment and street connectivity positively contribute to satisfaction (Lee et al., 2016; Novianto et al., 2016). Particularly, the suitability of streets for walking is found as a significant determinant for a better QoL (Ewing et al., 2006). In addition, green and open areas for pedestrians and handicapped people (Mohit, Ibrahim and Rashid, 2010; El Din et al., 2013; Novianto et al., 2016), adequacy of parking lots (Salleh, 2008; Gür and Dostoğlu, 2016) and appropriate width of streets seem to be considered factors associated with the quality of public spaces.

Quality of the social environment, as the third dimension, has a significant impact on QoL in neighbourhoods (Sedaghatnia et al., 2013). Quality of social relations is improved in a collective living environment and thus contributes to the creation of a sense of belonging and place attachment. In this respect, discreetness of inhabitants, social homogeneity in the area, calm and peaceful daily life and neighbourly relations are discussed in various studies and claimed to improve satisfaction from the neighbourhood (e.g. Bonaiuto, Fornara and Bonnes, 2003; Kahraman, 2013; Okumuş and Eyüboğlu, 2015; Gür and Dostoğlu, 2016).

Quality of the natural environment certainly affects human life and the QoL at all levels. Various issues associated with massive urbanisation such as increasing levels of air, water and noise pollution and loss of natural habitats and green areas negatively influence the subjective perception of individuals and their overall life satisfaction (e.g. Zanuzdana, Khan and Kraemer, 2012; Keleş, 2012; Novianto et al., 2016). Particularly at the neighbourhood level, problems related to maintenance and care of roads and public spaces (Şeker, 2011) concerning the existence of vacant and undeveloped areas (Hur and Nasar, 2014), illegal paintings on streets and inadequate street lighting (Okumuş and Eyüboğlu, 2015; Gür and Dostoğlu, 2016) have a negative correlation with QoL.

The fifth dimension of QoL in neighbourhoods is about safety and security. The feeling of insecurity in a built environment may affect people's QoL. The perceived risk from the physical environment with respect to accidents, violence and crimes (e.g. Salleh, 2008; Mohit, Ibrahim and Rasid, 2010; Gür and Dostoğlu, 2016; Schlesinger et al., 2016) and from the natural environment (Keleş, 2012; Novianto et al., 2016) 
are determined as factors in reducing the QoL. In this regard, particular attention has been devoted to understanding the factors posing a physical and emotional threat to life by considering particularly vulnerable groups such as women, children and the elderly (Ülengin, Ülengin and Güvenç, 2001; McCrea, 2007; Okumuş and Eyüboğlu, 2015).

Public service provision is accepted as a significant factor that shapes inhabitants' perception of QoL. Public services including health, education, transportation and infrastructure play a vital role in sustaining a social life. The existence and availability of welfare services were found significant in various contexts since the availability of these services and their relative proximity help to improve social well-being (e.g. Somarriba and Pena, 2008; Okumuş and Eyüboğlu, 2015; Novianto et al., 2016). Recreational and leisure services also influence wellbeing and life satisfaction. In particular, the adequacy and accessibility of cultural and sports facilities as well as parks, fountains and picnic areas are found significant (Kelekçi and Berköz, 2006; Santos and Martins, 2007; El Din et al., 2013; Zanuzdana, Khan and Kraemer, 2012). Similarly, commercial facilities and their variety within a neighbourhood in terms of shopping centres, small shops and banks influence the housing choice of individuals as they meet their daily requirements (Schlesinger et al., 2016; Gür and Dostoğlu, 2016). Finally, transportation and infrastructural services including the adequacy of public transportation modes and their frequency and variety (Kelekçi and Berköz, 2006; Insch and Florek, 2008; Keleş, 2012; Novianto et al., 2016), comfort and quality of public transit (Ülengin, Ülengin and Güvenç, 2001), as well as the quality of infrastructure are considered as important factors influencing QoL (Şeker, 2011; Zanuzdana, Khan and Kraemer, 2012; Keleş, 2012; Schlesinger et al., 2016).

Departing from the attributes measured both objectively and subjectively, this study aims to construct a framework in understanding personal evaluations of individuals of QoL at a neighbourhood level to assess the built, natural and social environment characteristics of a regenerated area.

\section{METHODOLOGY}

QoL in a neighbourhood depends on various individuals' choices and expectations which are hard to measure and interpret. There exists diverse literature on measuring QoL, but there is no uniform method agreed upon. This study proposes a methodology for measuring the QoL in neighbourhoods through the use of binary logistic regression with variables derived from the existing literature. Data was gathered through the application of a questionnaire based on a random sampling approach in the Akpinar neighbourhood of Ankara, which had 359 households residing in the area in December 2015. After collecting the data, a mixture of qualitative and quantitative analysis methods was employed to understand the QoL at the neighbourhood level. For quantitative techniques, descriptive statistics were used to obtain a measurable data set of individuals' subjective responses. Each indicator is designed on a five-point Likert scale in which 1 indicates "Not Important" and 5 refers to "Very Important". Following this, a regression analysis was conducted to examine the relationship between the overall QoL scores and the variables of quality of the built environment, public space, social and natural environment, services and safety. 


\section{Limitations}

Although this research has its roots in the self-evaluations of households in the neighbourhood, the findings obtained from the study can be generalised. The generalisability of the findings depends on the assumption that every society maintains a consensus on things that make people pleased or displeased. The primary limitation of the study is the accuracy of the data since self-reported information cannot be tested or verified. The information collected from the neighbourhood may tend to be overstated to draw attention to their pleasure or displeasure about the given indicator of QoL. Another potential limitation came from the number of respondents. Randomly selected dwelling units from all streets of the neighbourhood were visited by the pollsters. Unfortunately, some households refused to be a part of the research and did not accept to undertake the questionnaire, while some households could not be reached at the time of the survey. Owing to time and financial restrictions, this study could not produce an overall database for the case-study area. Rather, the research had to be limited to the results of the sampling area.

\section{Dependent variable}

To measure the QoL in a regenerated neighbourhood it is necessary to identify the dependent variable reflecting individuals' satisfaction. The evaluation of the dependent variable, overall QoL, is made through three variables, namely "neighbourhood satisfaction", "QoL in the neighbourhood" and "desire to move from the neighbourhood". For "neighbourhood satisfaction" and "QoL in the neighbourhood", respondents evaluated their satisfaction and QoL levels between 1 and 5. Additionally, the sample evaluates their desire to move from the neighbourhood with "yes" or "no" answers. Statements on willingness to move from the neighbourhood were coded as 0 to denote their negative contribution to the QoL in the neighbourhood. In sum, the overall QoL as the dependent variable of this study is an index of three variables ranging from 2 to 11, as shown in Table 1. In this range, 11 denotes the highest QoL level, while 2 indicates the lowest. The mean score on the overall QoL index in the sample was 8.

Table 1. The Overall QoL

\begin{tabular}{lccc}
\hline The Overall QoL & Mean & Minimum Value & Maximum Value $^{* *}$ \\
\hline $\begin{array}{l}\text { Satisfaction from the } \\
\text { neighbourhood }\end{array}$ & 3.805014 & 1 & 5 \\
$\begin{array}{l}\text { QoL in the neighbourhood } \\
\begin{array}{l}\text { Desire to move from the } \\
\text { neighbourhood }\end{array}\end{array}$ & 3.713092 & 1 & 5 \\
$\begin{array}{l}\text { The overall quality of the } \\
\text { neighbourhood }\end{array}$ & 0.660194 & 0 & 1 \\
\hline
\end{tabular}

Notes: "Overall Value of QoL in the Area (per household) = Mean Value of Satisfaction Level + Mean Value of QoL Level + Mean Value of Not Desire to Move.

"* Overall Maximum Value of QoL (per household) = Maximum Satisfaction Level + Maximum QoL Level + Value of Not Desire to Move. 


\section{Independent variables}

Based on inferences from the literature review and the contextual setting of the selected neighbourhood, the independent variables in explaining the overall QoL in the neighbourhood can be broadly grouped as the quality of the built environment, quality of public spaces, quality of social relations, quality of the environment, safety and quality of services and facilities. Under these six categories, a total of 46 independent variables were selected to run a regression analysis based on Likert scaling. All variables were measured on a five-point ordinal scale and their mean scores were obtained. Table 2 presents the descriptive statistics of the study's independent variables.

\section{EVALUATION OF QOL INDICATORS IN A REGENERATED NEIGHBOURHOOD}

Binary logistic regression was used to identify the factors of QoL in the Akpinar neighbourhood, through analysing the relationship between independent and dependent variables. Logistic regression revealed the relationship between overall QoL in the neighbourhood and 46 independent variables placed in subcategories. To run binary logistic regression, the dependent variable of "overall QoL in the neighbourhood", having values in the range between 2 and 11, was transformed into an ordinal measure. The mean satisfaction value of 8.1783 was determined as the breaking point. Respondents having a QoL score of less than 8 were coded as 0 to indicate dissatisfaction with the neighbourhood and those having scores higher than the mean were denoted as 1 to indicate satisfaction from the neighbourhood. For that account, among the 359 households, $73.3 \%$ were noted to be more satisfied with the QoL in Akpinar, while the remaining $26.7 \%$ were less satisfied with the QoL in the neighbourhood.

In the next step of the analysis, the logistic regression model was conducted to obtain the probability of a given dependent variable to assume a certain value. The analysis shows whether respondents are more likely to be satisfied with the QoL or not with respect to the independent variables. Table 3 reveals the results of the logistic regression for overall QoL in the Akpinar neighbourhood. The model correctly predicts $44 \%$ (Nagelkerke R Square) of the change in the dependent variable at the significance level of 0.001 . 


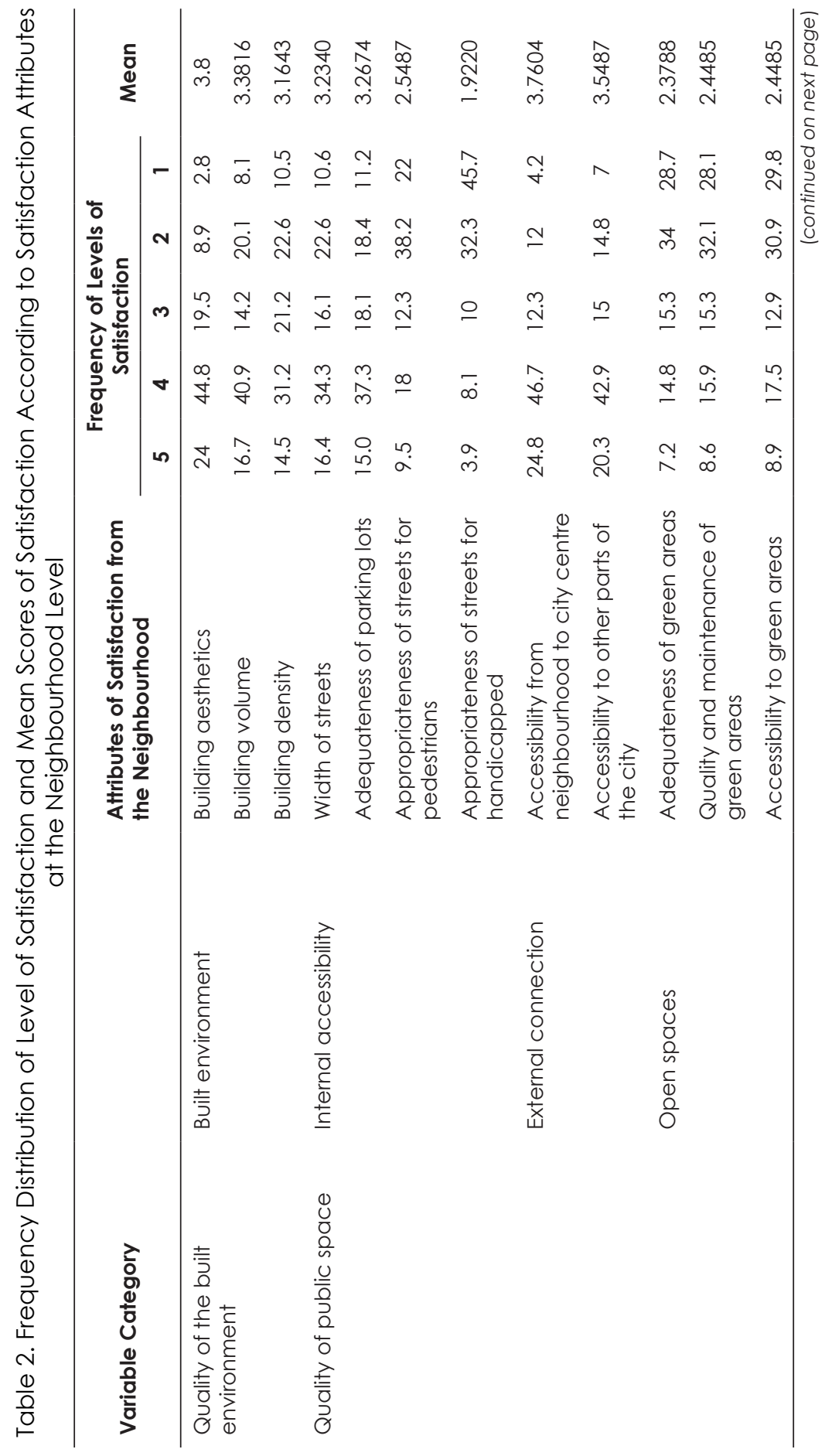




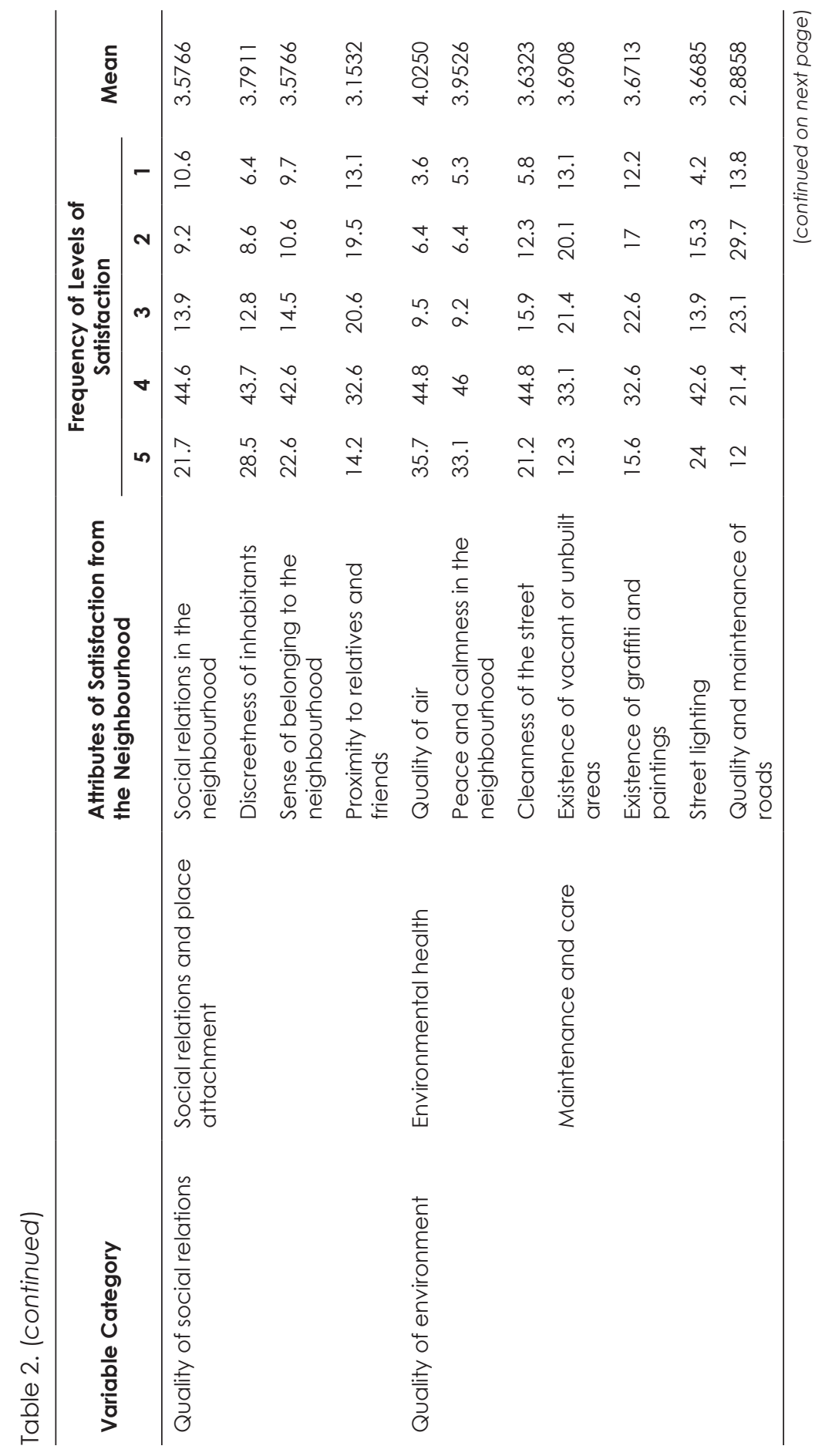




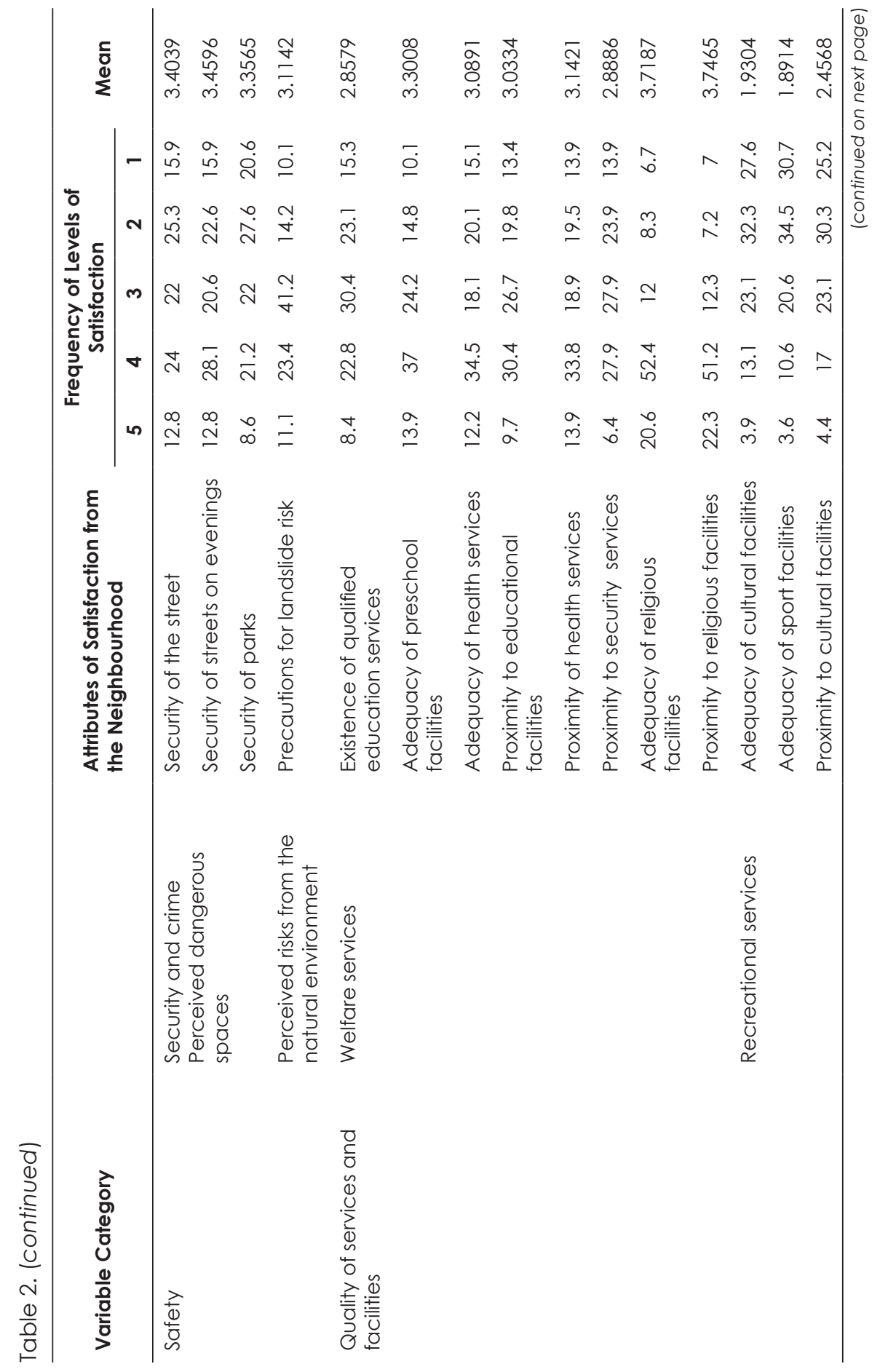




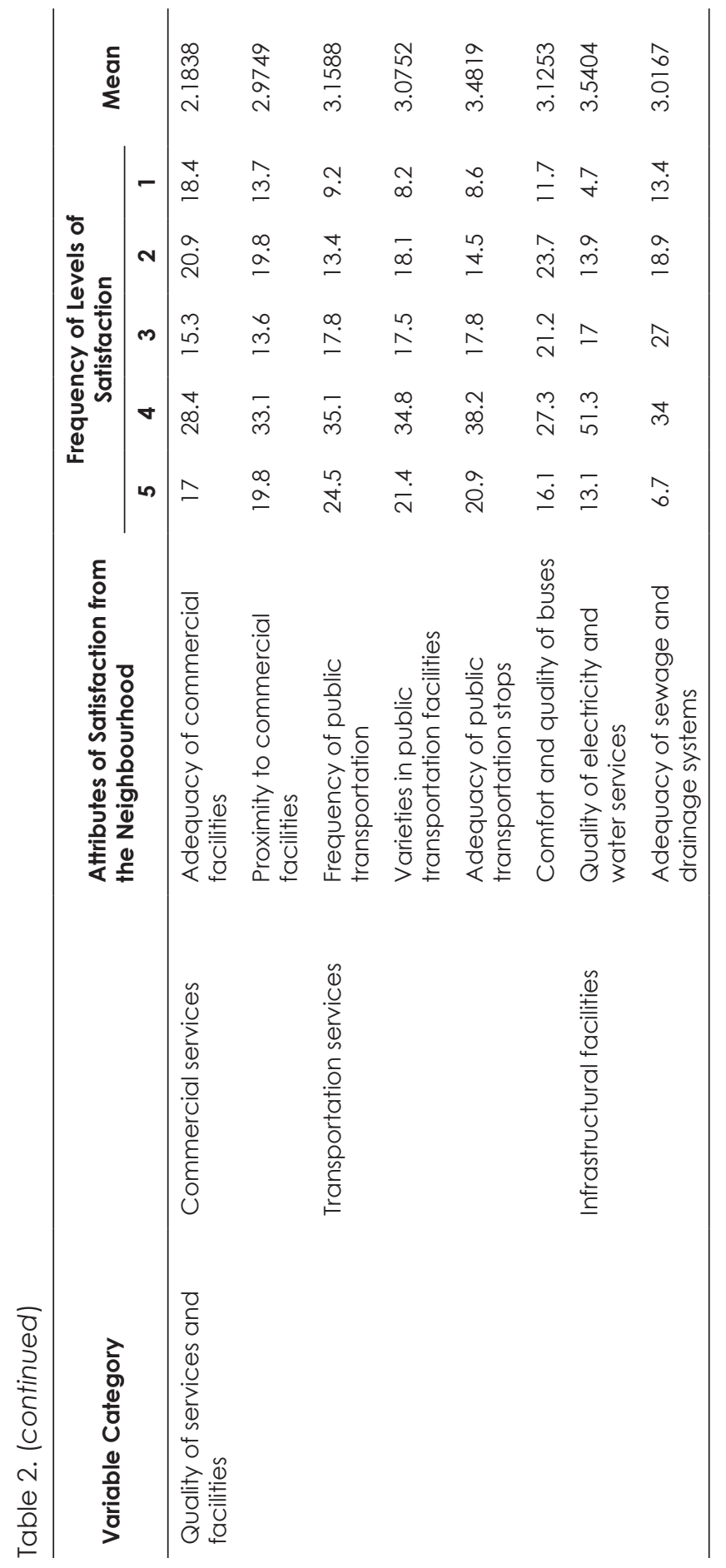




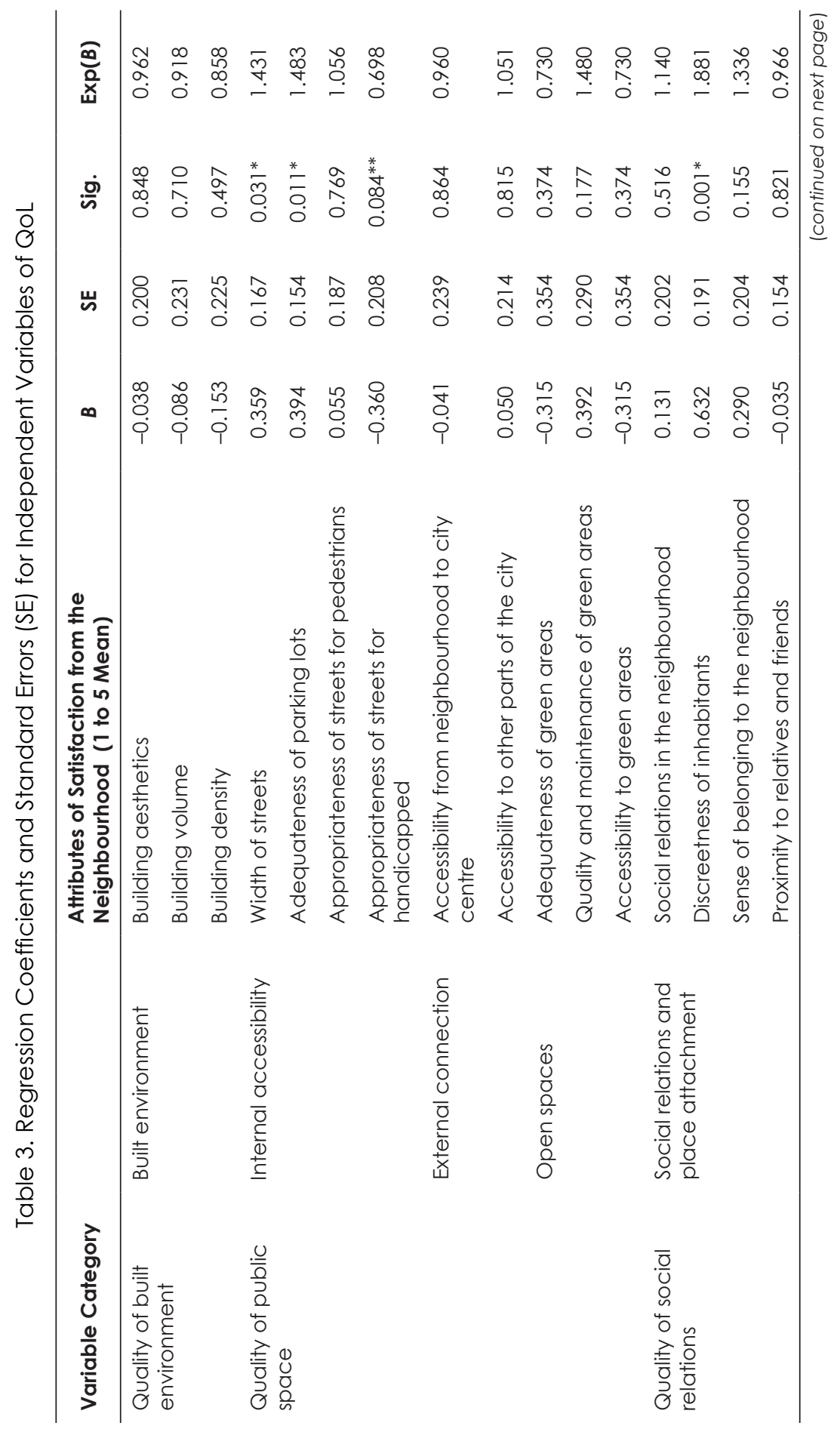




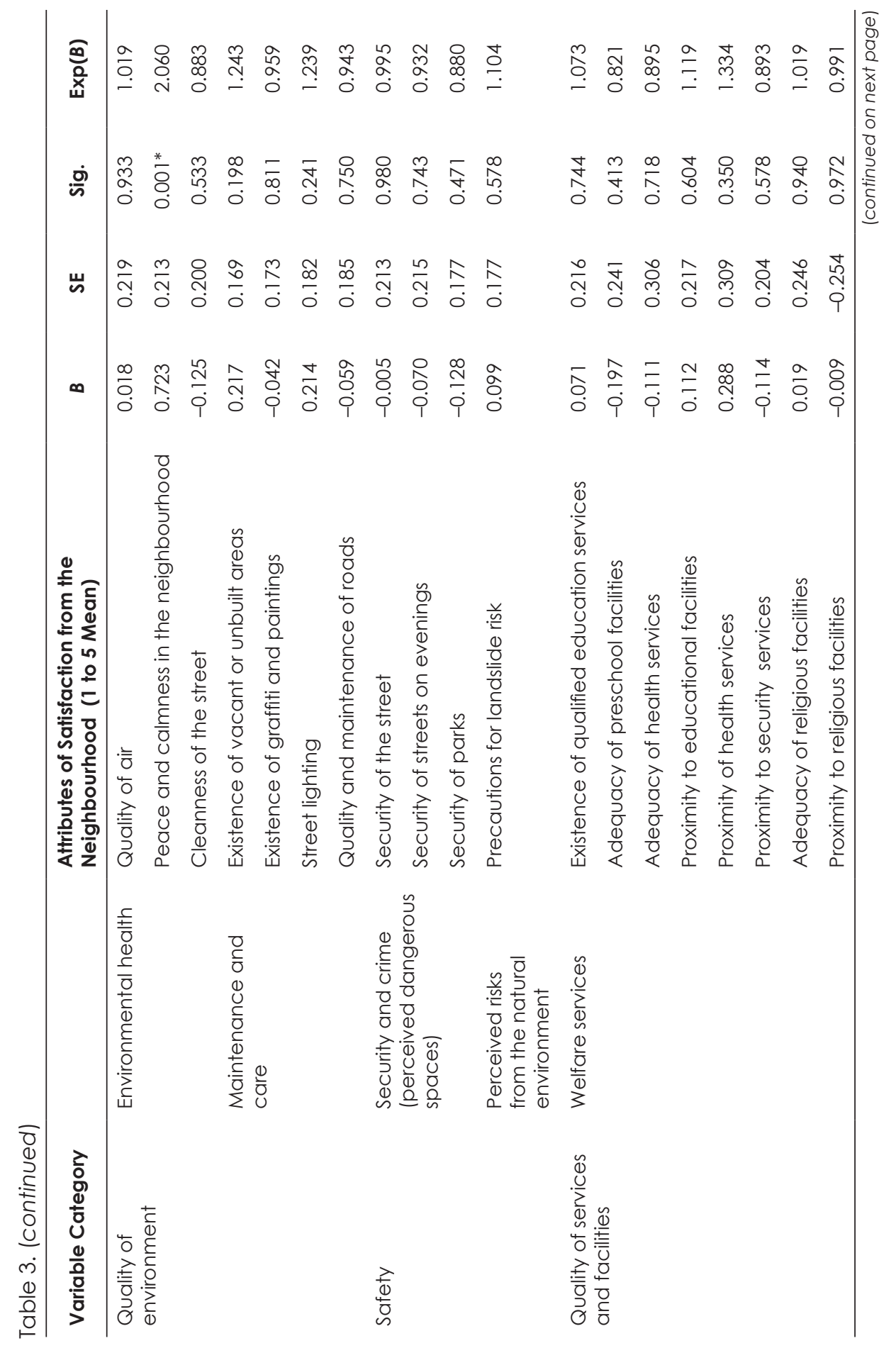




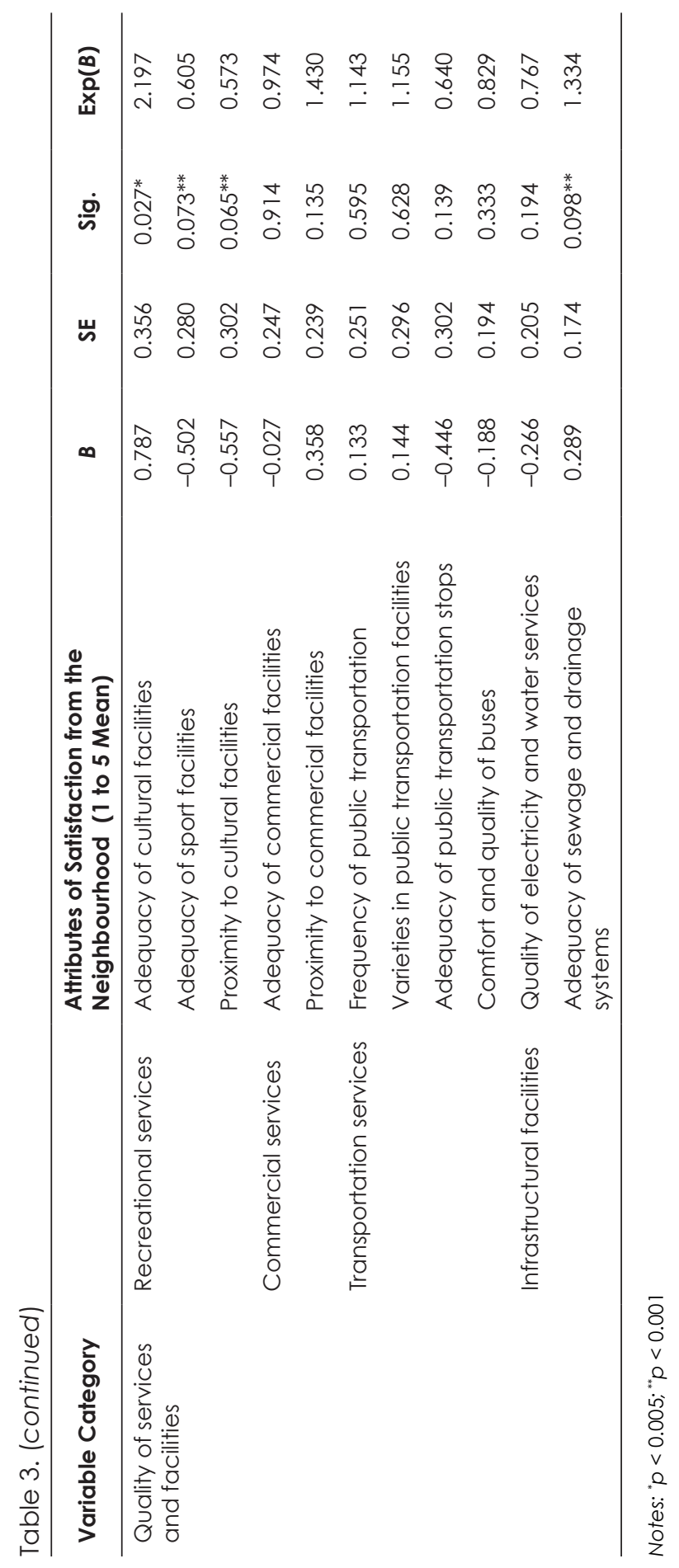


Among the regressed indicators of QoL in Akpinar, it is found that neighbourhood level QoL is positively predicted by the variables of the width of streets, adequacy of parking lots, adequacy of cultural facilities, adequacy of sewage and drainage system, discreetness of inhabitants and peace and calmness in the neighbourhood.

As expected, for quality of public space in the neighbourhood, in the Akpinar case, the width of streets and adequacy of parking lots are found to be positively related $(B=0.359 ; 0.394$, respectively) with the $Q$ oL at a significance level of 0.005 $(p<0.005)$. In other words, households are more likely to be satisfied with the QoL in their neighbourhood if they have wider streets and adequate parking lots, consistent with the findings of Salleh (2008) and Gür and Dostoğlu (2016). The demand for wide streets and adequate parking lots to safely leave private cars is reasonable for a neighbourhood where parking lots are not provided around or under the residential blocks.

Among regressed factors, discreetness of inhabitants seems one of the most determinant factors that positively correlated with the QoL in neighbourhoods $(p=0.001)$. Peace and calmness in the neighbourhood is another significant predictor of and positively associated with the QoL in the neighbourhood, with a significance level of $0.01(p=0.001)$. In this regard, the present analysis supported the expectation by emphasising the relationship between indicators of the social environment and QoL (Bonaiuto, Fornara and Bonnes, 2003; Kahraman, 2013; Okumuş and Eyüboğlu, 2015; Gür and Dostoğlu, 2016). A peaceful social environment and tolerance between inhabitants may indicate a socially stable life in the neighbourhood. Moreover, this outcome may be explained by the household profile, including gender, age, education and occupation. Those spending more time in the neighbourhood may demand a peaceful living environment which would, in turn, enhance their QoL. It can also be said that more educated households reveal more tolerance in keeping the peace and discreetness of the social milieu which would also improve the QoL.

Additionally, the adequacy of sewage and drainage systems is found to be positively associated $(B=0.289)$ with the level of satisfaction at a significance level of 0.1 , in parallel to the findings of Şeker (2011), Zanuzdana, Khan and Kraemer (2012), Keleş (2012) and Schlesinger et al. (2016). Due to the difficulty of topographical conditions that affect the daily life of residents, the adequacy of sewage and drainage systems is attached to the QoL. Although the neighbourhood has undergone a serious regeneration process and its whole infrastructure has been renewed, the lifeline system may be inadequate sometimes. Therefore, any investment made in such a lifeline system would enhance the QoL in the neighbourhood.

Interestingly, for the suitability of streets for handicapped people, the regression model $(p<0.1)$ presents a reverse relation with the QoL in the neighbourhood $(B=-0.360)$. This may be explained through the difficulty of topographical conditions and continuous construction of pedestrian walkways which may reduce the ability for handicapped people to live in a well-designed environment.

Among the indicators of quality of public services and facilities, adequacy of cultural facilities $(p<0.05)$ and proximity to such facilities $(p<0.1)$ are found to be significant. According to the results, the $Q O L$ is positively associated with the adequacy of cultural facilities ( $B=0.787)$, whereas being close to them is negatively associated $(B=-0.557)$. These contradictory findings may be explained through the proximity of Akpinar to the central parts of the city, which offer a 
wider variety of opportunities. Although residents demand more cultural facilities in the neighbourhood, which is likely to increase the QoL, the closeness of the neighbourhood to the central district may prevent the development of such facilities in the immediate neighbourhood.

Another significant relation in a negative direction is found between $Q$ oL and the adequacy of sports facilities $(B=-0.502)$. As a recreational urban element, of these facilities, might be expected to create a positive contribution to satisfaction in the neighbourhood. However, the negative correlation can be explained through the fact that the residents of Akpinar are not particularly interested in sports and do not need such facilities to enhance their QoL.

\section{CONCLUSION}

Urban regeneration efforts play a significant role as a planning instrument in responding to the deprived economic, social and physical structures of cities. One of the main motivations behind these efforts is to enhance QoL in the given environment. However, measuring the success of regeneration projects is difficult as the benefits of the regeneration do not necessarily reflect monetary outcomes. Rather, QoL improvement in a regenerated area can be assessed through subjective indicators sensitive to locational and communal factors.

This article focused on the underlying factors that determine the QoL levels of households since everyone's perception of QoL is different (Zehner, 1977). In examining the differences, it was hypothesised that the QoL in a regenerated neighbourhood is related to the quality of the built environment, public spaces, the social and natural environments, services and facilities and safety. Thus, 46 indicators depicting the social, physical, environmental and spatial dimensions of life were identified and the overall QoL of residents was analysed through those selected indicators.

In line with the preceding remarks, it is suggested that urban regeneration efforts need to enlarge their policy and practice schema to a wider extent. This study shows that urban regeneration, when applied with a focus on housing renewal, needs to be further cultivated. Neglecting the infrastructural and social services does not utilise the regeneration opportunities to improve environmental qualities. As can be seen in the Akpinar case, the regeneration process has dramatically changed the neighbourhood. The results of the study showed that regeneration in the studied neighbourhood was practised with an emphasis on a physical transformation of the housing environment, but not properly applied to the improvement of the infrastructural and social services. According to the subjective statements of respondents, satisfaction from recreation and commercial facilities and internal accessibility within the neighbourhood were low. Moreover, the findings revealed that overall QoL of residents was positively associated with the indicators concerning the width of streets, adequacy of parking lots, discreetness of inhabitants, peace in the neighbourhood, adequacy of cultural facilities and adequacy of sewage and drainage systems. Therefore, to increase liveability, it is essential for decision-makers to focus on community-related problems. In this regard, priority should be given to social services and lifeline systems to enhance the QoL at an aggregate level. Provision of such facilities is highly important for the residents, especially those who are vulnerable or disadvantaged in accessing 
them. Besides, as the QoL was attached to the peace in the neighbourhood, those factors that negatively affect the social environment should be discouraged.

Further research on QoL based on subjective statements, such as those outlined in this article, should be supported to develop policy guidelines in regeneration processes. Subjective assessments enable an understanding of different needs and expectations, the perceived quality of the environment, capabilities and inequalities, which are often overlooked in both public policies and urban planning decisions. Rather than being limited to the official figures depicting national or regional level socio-economic status, this study underlines the need for evaluating the subjective statements of people to assess the variations among them. Such broader figures may not necessarily reflect the QoL for a community's living environment, i.e. at the neighbourhood level, so a comprehensive schema, as present in this article, should be developed to evaluate the direct effects of multi-dimensional aspects of life. It is equally important to monitor the major problem areas for the improvement of QoL. Regeneration policies are applied to overcome the deterioration of the social, economic and physical environment. The investment allocated for regeneration should respond to the needs of the residents and be as comprehensive as possible to achieve its goals. Therefore, other social, cultural, political and economic aspects may also affect the QoL and thus should be included in policy making and planning processes in regenerated neighbourhoods.

\section{REFERENCES}

Alberini, P., Riganti, P. and Longo, A. (2003). Can people value the aesthetic and use services of urban sites? Evidence from a survey of Belfast residents. Journal of Cultural Economics, 27(3-4): 193-213. https://doi. org/10.1023/A:1026317209968.

Batson, C.D. and Monnat, S.M. (2015). Distress in the desert: Neighbourhood disorder, resident satisfaction and quality of life during the Las Vegas foreclosure crisis. Urban Affairs Review, 51(2): 205-238. https://doi. org/10.1177/1078087414527080.

Bonaiuto, M., Fornara, F. and Bonnes, M. (2003). Indexes of perceived residential environment quality and neighbourhood attachment in urban environments: A confirmation study on the city of Rome. Landscape and Urban Planning, 65(1): 41-52. https://doi.org/10.1016/S0169-2046(02)00236-0.

Campbell, A., Converse, P. and Rodgers, W. (1976). The Quality of American Life: Perceptions, Evaluations and Satisfactions. New York: Russell Sage Foundation.

Diener, E. and Suh, E. (1997). Measuring quality of life: Economic, social and subjective indicators. Social Indicators Research, 40: 189-216. https://doi. org/10.1023/A:1006859511756.

El Din, H.S., Shalaby, A., Farouh, H.E. and Elariane, S.A. (2013). Principles of urban quality of life for a neighbourhood. HBRC Journal, 9(1): 86-92. https://doi. org/10.1016/j.hbrcj.2013.02.007.

Ewing, R., Handy, S., Brownson, R. C., Clemente, O. and Winston, E. (2006). Identifying and measuring urban design qualities related to walkability. Journal of Physical Activity and Health, 3(1): 223-240. https://doi.org/10.1123/jpah.3.s1. s223. 
Gür, M. and Dostoğlu, N. (2016). Bursa Doğanbey üzerinden kentsel dönüşümde yaşam kalitesinin tartışılması. Megaron, 11 (1): 89-105.

Hemphill, L., Berry, J. and McGreal, S. (2004). An indicator-based approach to measuring sustainable urban regeneration performance: Part 1, Conceptual foundations and methodological framework. Urban Studies, 41 (4): 725-755. https://doi.org/10.1080/0042098042000194089.

Hur, M. and Nasar, J.L. (2014). Physical upkeep, perceived upkeep, fear of crime and neighbourhood satisfaction. Journal of Environmental Psychology, 38: 186-194. https://doi.org/10.1016/j.jenvp.2014.02.001.

Insch, A. and Florek, M. (2008). A great place to live, work and play: Conceptualising place satisfaction in the case of a city's residents. Journal of Place Management and Development, 1(2): 138-149. https://doi. org/10.1108/17538330810889970.

Kahraman, Z.E. (2013). Dimensions of housing satisfaction: A case study based on perceptions of rural migrants living in Dikmen. METU Journal of Faculty of Architecture, 30(1): 1-27. https://doi.org/10.4305/METU.JFA.2013.1.1.

Kelekçi, Ö.L. and Berköz, L. (2006). Mass housing: User satisfaction in housing and its environment in Istanbul, Turkey. European Journal of Housing Policy, 6(1): 77-99. https://doi.org/10.1080/14616710600587654.

Keleş, R. (2012). The quality of life and the environment. Procedia - Social and Behavioural Sciences, 35: 23-32. https://doi.org/10.1016/j.sbspro.2012.02.059.

Lee, S.M., Conway, T.L., Frank, L.D., Saelens, B.E., Cain, K.L. and Sallis, J.F. (2016). The relation of perceived and objective environment attributes to neighbourhood satisfaction. Environment and Behaviour, 49(2): 136-160. https://doi. org/10.1177/0013916515623823.

Marans, R.W. (2003). Understanding environmental quality through quality of life studies: The 2001 DAS and its use of subjective and objective indicators. Landscape and Urban Planning, 65(1-2): 73-83. https://doi.org/10.1016/ S0169-2046(02)00239-6.

McCrea, P. (2007). Urban quality of life: Linking objective dimensions and subjective evaluations of the urban environment. PhD diss., University of Queensland.

Mohit, M.A., Ibrahim, M. and Rashid, Y.R. (2010). Assessment of residential satisfaction in newly designed public low-cost housing in Kuala Lumpur, Malaysia. Habitat International, 34(1): 18-27. https://doi.org/10.1016/j.habitatint.2009.04.002.

Myers, D. (1988). Building knowledge about quality of life for urban planning. Journal of the American Planning Association, 54(3): 347-358. https://doi. org/10.1080/01944368808976495.

Novianto, D., Gao, W., Kuroki, S. and Fukahori, H. (2016). Statistical evaluation on neighborhood facilities in relation with residential satisfaction and preference. American Journal of Environmental Sciences, 12(3): 169-181. https://doi. org/10.3844/ajessp.2016.169.181.

Okumuş, D.E. and Eyüboğlu, E.E. (2015). A pre-application method for urban regeneration projects using qualitative and quantitative indicators of urban quality of life in Istanbul's Ataşehir Barbaros neighbourhood. Planlama, 25(2): 93-106. https://doi.org/10.5505/planlama.2015.09709.

Pacione, M. (2003). Urban environmental quality and human wellbeing: A social geographical perspective. Landscape and Urban Planning, 65(1-2): 19-30. https://doi.org/10.1016/S0169-2046(02)00234-7.

Roberts, P. and Sykes, H. (2000). Urban Regeneration: A Handbook. London/ Thousand Oaks/New Delhi: SAGE Publications. 
Salleh, A.G. (2008). Neighbourhood factors in private low-cost housing in Malaysia. Habitat International, 32(4): 485-493. https://doi.org/10.1016/j. habitatint.2008.01.002.

Santos, L.D. and Martins, I. (2007). Monitoring urban quality of life: The Porto experience. Social Indicators Research, 80(2): 411-425. https://doi. org/10.1007/s 1 1205-006-0002-2.

Schlesinger, W., Taulet, A.C., Alves, H. and Burguete, J.L.V. (2016). An approach to measuring perceived quality of life in the city through a formative multidimensional perspective. In J. Leitão and H. Alves (eds.), Entrepreneurial and Innovative Practices in Public Institutions: A Quality of Life Approach. Cham, Switzerland: Springer International Publishing. https://doi. org/10.1007/978-3-319-32091-5_4.

Sedaghatnia, S., Lamit, H., Ghahramanpouri, A. and Mohamad, S. (2013). An evaluation of residents' quality of life through neighbourhood satisfaction in Malaysia. Environmental Management and Sustainable Development, 2(1): 114-125. https://doi.org/10.5296/emsd.v2i1.3254.

Şeker, M. (2011). İstanbulıda Yaşam Kalitesi Araştırması. Istanbul: İstanbul Ticaret Odası Yayınları.

Shin, D.C. and Johnson, D.M. (1978). Avowed happiness as an overall assessment of the quality of life. Social Indicators Research, 5(1-4): 475-492. https://doi. org/10.1007/BF00352944.

Somarriba, N. and Pena, B. (2008). Synthetic indicators of quality of life in Europe. Social Indicators Research, 94: 115-133. https://doi.org/10.1007/s1 1205-0089356-y.

Ülengin, B., Ülengin, F. and Güvenç, Ü. (2001). A multidimensional approach to urban quality of life: The case of Istanbul. European Journal of Operational Research, 130(2): 361-374. https://doi.org/10.1016/S0377-2217(00)00047-3.

Zanuzdana, A., Khan, M. and Kraemer, A. (2012). Housing satisfaction related to health and importance of services in urban slums: Evidence from Dhaka, Bangladesh. Social Indicators Research, 112(1): 163-185. https://doi. org/10.1007/s1 1205-012-0045-5.

Zehner, R. (1977). Indicators of the Quality of Life in New Communities. Cambridge: Ballinger. 